\title{
Hyperadiponectinemia During Infliximab Induction Therapy in Pediatric Crohn Disease
}

\author{
${ }^{* \dagger}$ Klara Frivolt, ${ }^{*}$ Tobias Schwerd, ${ }^{*}$ Stephanie B. Schatz, ${ }^{* \ddagger}$ Folke Freudenberg, \\ ${ }^{*}$ Christine Prell, ${ }^{*}$ Katharina J. Werkstetter, ${ }^{*}$ Philip Bufler, and ${ }^{*}$ Sibylle Koletzko
}

\begin{abstract}
Objectives: The inflammatory process in Crohn disease (CD) involves the visceral fat, characterized by adipocyte hyperplasia and altered adipose tissue and serum concentrations of tumor necrosis factor (TNF), leptin, adiponectin and resistin. We investigated the effect of anti-TNF therapy with infliximab (IFX) on serum adipokine levels in pediatric CD.

Methods: Serum concentrations of resistin $(\mathrm{ng} / \mathrm{mL})$, leptin $(\mathrm{ng} / \mathrm{mL})$, and total adiponectin $(\mu \mathrm{g} / \mathrm{mL})$ were assessed by enzyme-linked immunosorbent assays (ELISA) in 18 pediatric CD patients (mean age $15.0 \pm 1.5$ years) before first, second, and fourth IFX infusion (weeks 0, 2, and 14) and compared with baseline values from sex- and BMI-matched healthy controls ( $\mathrm{HC}$, mean age $13.4 \pm 1.6$ years).

Results: At baseline, CD patients (mean age $15.0 \pm 1.5$ years, 10 of 18 boys) compared with $\mathrm{HC}$ (13.4 \pm 1.6 years, 7 of 15 boys) had higher resistin levels (median $14.7 \mathrm{ng} / \mathrm{mL}$, range $5.1-50.5 \mathrm{vs} 7.3 \mathrm{ng} / \mathrm{mL}, 0.5-14.5$ ); $P=0.0002$ ). At weeks 2 and 14 , resistin decreased to $6.9 \mathrm{ng} / \mathrm{mL}(2.9-16.8)(P<0.0001)$ and $9.2 \mathrm{ng} / \mathrm{mL}(4.1-20.6 ; P=0.0011)$, respectively. Leptin and adiponectin were comparable between patients and $\mathrm{HC}$ at baseline. Leptin increased in girls from $9.5 \mathrm{ng} / \mathrm{mL}(4.0-30.1)$ to $16.0 \mathrm{ng} / \mathrm{mL}(7.9-35.2 ; P=0.0156)$ and $17.2 \mathrm{ng} / \mathrm{mL}(10.8-26.8 ; P=0.1953)$ at weeks 0,2 , and 14 respectively; with a trend in boys from $2(0.6-12.9)$ to $2.8(1.7-8.6 ; P=0.0840)$ and $3.3(1.3-$ 4.6; $P=0.1309)$. Adiponectin peaked initially from $7.8 \mu \mathrm{g} / \mathrm{mL}(4.6-11.9)$ at week 0 to $9.2 \mu \mathrm{g} / \mathrm{mL}(4.1-20.7 ; P=0.0005)$ at week 2 and thereafter fell to $6.5 \mu \mathrm{g} / \mathrm{mL}(3.0-12.7 ; P=0.0182)$ at week 14 .

Conclusions: TNF blockade is associated with changes in circulating adipokines. The marked early increase of the potent anti-inflammatory adiponectin may contribute to the rapid response to IFX in CD.
\end{abstract}

Key Words: adipokines, infliximab, pediatric Crohn disease

(JPGN 2018;66: 915-919)

Received July 27, 2017; accepted November 14, 2017

From the *Dr. von Hauner Children's Hospital, Department of Pediatrics, University Hospital, LMU Munich, Munich, Germany, the tDepartment of Pediatrics, Comenius University Medical School, Bratislava, Slovakia, and the $\ddagger$ Paediatric Clinic in Dritter Orden Clinic, Munich, Germany.

Address correspondence and reprint requests to Sibylle Koletzko, MD, Dr. von Hauner Children's Hospital, Department of Pediatrics, University Hospital, LMU Munich, Lindwurmstr. 4, 80337 München, Germany (e-mail: Sibylle.Koletzko@med.uni-muenchen.de).

Dr Klara Frivolt, a young pediatrician in training at the University of Bratislava, died on August 5, 2017 in Hungary being pregnant with her second child. Klara had spent two research periods of 18 months each at the Division of Gastroenterology and Hepatology at the Dr von Hauner Children's Hospital, LMU Munich, Germany. She had received several research awards including the Nestle Nutrition Award from the European Crohn and Colitis Organization (ECCO) in 2014. On July 4, 2017 she successfully defended her $\mathrm{PhD}$. Klara Frivolt was an extremely talented young physician scientist and a wonderful person. We are in deep grief.

\section{What Is Known}

- Mesenteric adipose tissue hyperplasia near the inflamed intestine is characteristic for Crohn disease, represents an important source of different pro- and anti-inflammatory mediators and is associated with altered serum adipokine concentrations.

- Resistin levels have been suggested as a biomarker of successful anti-tumor necrosis factor (anti-TNF) therapy, whereas leptin and adiponectin concentrations reflect body fat mass in opposite manner.

\section{What Is New}

- Tumor necrosis factor (TNF) blockade is associated with a rapid increase of the anti-inflammatory adiponectin in pediatric Crohn disease, which may contribute to effective induction therapy.

- Measurements of serum adipokines may serve as a biomarker for short- and long-term response to infliximab.

W hen Crohn et al (1) first described Crohn disease (CD) in the early 1930s, they noticed increased mesenteric adipose tissue attached to the inflamed intestine. The importance in the pathogenesis and course of the disease, however, caught only

K.F. was supported by the National Scholarship Program of the Slovak Republic, Collegium Talentum and SPP Foundation, and by a grant from Ministry of Education of the Slovak Republics [\#VEGA 1/1267/12] and an ECCO Fellowship. This work was supported in part by a grant of the Friedrich Baur Foundation [FBS No 50/11]. T.S. was supported by the Ludwig-Maximilians-University Munich [FöFoLe 742] and received travel support from Nestlé and speaker's fees from MSD. K.J.W. received a grant [FöFoLe 968/2017] from the Ludwig-Maximilians-University Munich. P.B. received honorarium as speaker from GivenImaging, Abbvie, Abbott, Roche and MSD. S.K. received a research grant from Mead Johnson and Nestlé Nutrition, and honorarium as speaker or advisory board member from Abbott, Danone, Hipp, MSD, ThermoFisher. C.P. received a research grant from Mead Johnson Nutrition, and honorarium as speaker from Hipp and Alexion Pharmaceuticals. The remaining authors report no conflicts of interest.

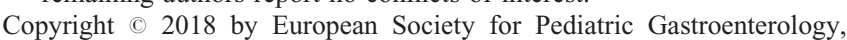
Hepatology, and Nutrition and North American Society for Pediatric Gastroenterology, Hepatology, and Nutrition

DOI: 10.1097/MPG.0000000000001876 
attention in the last 2 decades. Initially, it was suggested that mesenteric adipose tissue inflammation precedes mucosal inflammation and represents a causative factor in the pathogenesis of $C D(2,3)$. More recent findings conclude that the hyperplasia of the mesenteric adipose tissue is a protective mechanism to improve barrier function against bacterial translocation through the inflamed gut (4).

Visceral adipose tissue is a dynamic endocrine and paracrine organ, which participates in the regulation of metabolism and acts as an active innate immune organ (5). It was shown that not only the mesenteric adipose tissue attached to the inflamed intestine but also the omental adipose tissue more distant from the inflamed intestine is affected by inflammation in CD (6), and represents a source of pro- and anti-inflammatory cytokines and chemokines (3,4,7-10). Preadipocytes and adipocytes are immunologically active cells expressing pattern recognition receptors and secreting inflammatory mediators (11). Furthermore, pre-adipocytes have phagocytic and antimicrobial activity similar to macrophages (12). Two major players in the family of adipose tissue-derived cytokines, so called adipokines, are leptin and adiponectin. Although leptin is attributed a rather pro-inflammatory role, adiponectin has potent anti-inflammatory effects $(13,14)$. In contrast to leptin, changes in body fat correlate inversely with adiponectin levels (15). Adiponectin is present in high amounts in the circulation and has several isoforms that bind specifically to 2 types of adiponectin receptors. The proinflammatory resistin increases during inflammation and is produced in humans not only in adipocytes but also in macrophages and peripheral blood mononuclear cells (16).

The mesenteric adipose tissue of CD patients is involved in the inflammatory process indicated by increased tissue concentrations of tumor necrosis factor (TNF) (3), C-reactive protein (CRP) (10), resistin and leptin $(7,8)$ but also of various other anti-inflammatory cell mediators, including adiponectin $(8,9)$. In vitro TNF inhibits leptin and adiponectin expression but stimulates the release of resistin $(15,17,18)$. Alterations in serum adipokine levels have been reported in both pediatric and adult CD patients (19-24).

The monoclonal chimeric anti-TNF antibody infliximab (IFX) is a highly effective induction and maintenance treatment in patients with severe and complicated CD $(25,26)$. The aim of this study was to investigate whether the TNF blockade by IFX modulates circulating adipokine levels in pediatric $C D$ during the induction phase. Baseline adipokine levels were compared with concentrations found in sex- and body mass index (BMI)-matched healthy control children.

\section{METHODS}

This retrospective case control study was approved by the Ethics Committee of the Medical Faculty of the LudwigMaximilian University in Munich.

\section{Patients and Controls}

Patients with $\mathrm{CD}$ were eligible for inclusion if they were treated with IFX at Dr. von Hauner Children's Hospital in Munich and had frozen serum samples available taken before the first, second, and fourth IFX infusion (weeks 0, 2, and 14). Serum is routinely sampled before each infusion and directly stored at $-20^{\circ} \mathrm{C}$ to allow the measurement of IFX trough levels or antibodies against IFX, in case, the patient shows an allergic adverse reaction during or after the infusion or loss of response. Exclusion criteria were prior treatment with an anti-TNF antibody.

CD was diagnosed in all patients according to Porto criteria (27). The phenotype was assessed according to the Paris classification (28). IFX was given as intravenous induction therapy $(5 \mathrm{mg} / \mathrm{kg}$ per dose) at 0,2 , and 6 weeks, followed by a maintenance treatment, every 8 weeks (29). Disease activity, laboratory, and anthropometric parameters before and during therapy were compared with adipokine levels. As serum levels of leptin and adiponectin are affected by sex and body composition, results were compared with adipokine concentrations measured in anonymized serum samples of 15 healthy sex- and BMI-matched adolescents obtained by Freudenberg et al (30).

\section{Data Collection and Patient Evaluation}

Electronic health care records and patient files were used to collect data before IFX initiation, at second and fourth IFX infusion (weeks 0,2, and 14). Concomitant medications (eg 5-aminosalycilates, azathioprine, or corticosteroids) were recorded. At all visits, clinical, anthropometric, and laboratory parameters (C-reactive protein [CRP], erythrocyte sedimentation rate [ESR], serum albumin, and hematocrit) were assessed, which allowed calculation of the mathematically weighted Pediatric Crohn's Disease Activity Index (wPCDAI, range 0-125). Remission was defined as wPCDAI $<12.5$ points, mild disease as wPCDAI $\geq 12.5$ points but $<40$ points, wPCDAI $\geq 40$ points indicated moderate, and wPCDAI $\geq 57.5$ points severe disease activity (31). Responders were defined as being in remission at week 14. Partial responders were patients with small (change in wPCDAI $>17.5$ points) or moderate improvement (change in wPCDAI $>37.5$ points) in disease activity but not achieving remission at week 14 . Non-responders achieved neither improvement nor remission until week 14 .

\section{Immunoassays}

All serum samples of patients and controls were stored at $-20{ }^{\circ} \mathrm{C}$ until measurement. Resistin, leptin (Human Leptin and Resistin Quantikine ELISA Kits, R\&D Systems, Minneapolis, MN) and total adiponectin (Total Adiponectin ELISA Kit, ALPCO Diagnostics, Salem, NH) serum levels were assessed with commercially available enzyme-linked immunosorbent assays (ELISA) according to the manufacturer's instructions.

\section{Statistical Analysis}

Continuous variables are expressed as medians (range) or means \pm standard deviation. Wilcoxon matched-pairs signed rank test was applied to analyze differences between changes in nonparametric data between IFX patients and healthy controls (HC). For comparison of parametric data paired $t$-test and for sex differences Mann-Whitney $U$ test was applied. Spearman correlation analysis was used to determine correlation significance between adipokines and disease activity, inflammatory and anthropometric parameters. Results are expressed as correlation coefficient $(r)$ and exact $P$ value. Statistical analyses were performed using GraphPad Prism version 6.00 for Mac OS X (GraphPad Software Inc., La Jolla, CA). $P$ values below 0.05 were considered statistically significant.

\section{RESULTS}

Baseline patient characteristics are provided in Table 1. Eighteen patients (10 boys) were eligible, with a mean age at diagnosis of $12.0 \pm 2.2$ years and a mean age at IFX initiation of $15.0 \pm 1.5$ years. Four patients had stricturing and 1 stricturing and penetrating disease behavior, whereas 7 of 18 presented with perianal involvement. Indications for biological therapy were complicated or perianal disease $(n=10)$, relapse or persistent inflammation despite immunomodulatory therapy $(\mathrm{n}=8)$. All 18 patients 


\begin{tabular}{lc}
\hline TABLE 1. Baseline patient characteristics & \\
\hline & Infliximab patients \\
\hline Gender (male/female) & $10 / 8$ \\
Mean age $( \pm \mathrm{SD})$ at therapy initiation & $15.0 \pm 1.5$ years \\
Mean age $( \pm \mathrm{SD})$ at diagnosis & $12.0 \pm 2.2$ years \\
Extraintestinal manifestation & $2 / 18$ \\
Disease location & $7 / 18$ \\
L1 Terminal ileum & $3 / 18$ \\
L2 Colon & $8 / 18$ \\
L3 Ileocolonic & $10 / 18$ \\
+ L4 (upper GI tract) & \\
Disease behavior & $13 / 18$ \\
B1 nonstricturing-nonpenetrating & $4 / 18$ \\
B2 stricturing & $0 / 18$ \\
B3 penetrating & $1 / 18$ \\
B2B3 penetrating and structuring & $7 / 18$ \\
Perianal involvement & \\
Associated medical therapy & $15 / 18$ \\
5-aminosalycilic acid & $18 / 18$ \\
Azathioprine & $2 / 18$ \\
Systemic corticosteroids & $3 / 18$ \\
Budesonide &
\end{tabular}

$\mathrm{GI}=$ gastrointestinal; $\mathrm{SD}=$ standard deviation.

were treated with azathioprine on a stable dose for at least 3 months, 2 received systemic steroids, and 3 budesonide before or during IFX-induction therapy.

The 15 sex- and BMI-matched HC were younger compared with CD patients with a mean age of $13.4 \pm 1.6$ years $(P=0.0033)$. Table 2 depicts anthropometric characteristics of $\mathrm{HC}$ and patients.

\section{Disease Activity and Inflammatory Parameters Under Infliximab}

According to wPCDAI, 1 of 18 patients had severe and 7 of 18 had moderate disease activity. Indication for IFX in 5 of 10 patients with mild disease was perianal involvement with severe fistula and in 1 patient, presence of internal fistulas. IFX decreased overall disease activity, normalized inflammatory parameters after 2 and 14 weeks, respectively (Table 2) and induced remission in 13 of 18 patients. We detected partial response with moderate improvement in disease activity in 3 patients with stricturing disease. Two patients with complex perianal fistulas did not respond to treatment.

\section{Serum Adipokine Levels in Health and Disease}

Serum adipokine levels are listed in Table 2. At baseline, resistin levels were significantly elevated in patients compared with HC. Resistin significantly decreased under IFX (Fig. 1A). There was no difference in resistin concentrations between boys and girls. Baseline resistin concentrations correlated with CRP $(r=0.549$, $P=0.018)$ and the decrease after 2 and 14 weeks correlated with improvement in CRP $(r=0.614, P=0.007$ and $r=0.665$, $P=0.003$, respectively). Similarly, resistin correlated with wPCDAI. This correlation was significant but weak $(r=0.316$, $P=0.02$ ). Leptin levels in boys were significantly lower compared with girls (at 0,2, and 14 weeks). Before IFX, leptin did not differ between patients and $\mathrm{HC}$ but increased in CD patients under IFX (Fig. 1B). Baseline adiponectin levels were similar in CD patients and $\mathrm{HC}$ and tended to be lower in boys. Adiponectin significantly increased after the first IFX infusion but decreased after 14 weeks to levels lower than at week 2, at baseline or in HC (Fig. 1C).

\section{DISCUSSION}

Using magnetic resonance imaging studies in pediatric $C D$ patients, we could recently show that intra-abdominal adipose tissue is increased compared with non-CD children and correlates with disease duration (32). During IFX treatment, a homogenous increase in both subcutaneous- and intra-abdominal adipose tissue was observed in adults (33). In this retrospective study, we show that induction therapy with IFX induced early changes in circulating adipokines in pediatric $\mathrm{CD}$ with a significant increase of adiponectin, a potent antiinflammatory compound, after the first infusion.

Resistin is a pro-inflammatory adipokine expressed mainly in peripheral blood mononuclear cells (PBMCs) and partially in

\begin{tabular}{|c|c|c|c|c|c|c|c|c|}
\hline & $\mathrm{HC}$ & $P(\mathrm{HC}$ vs w0) & Week 0 & $P($ w0 vs w2) & Week 2 & $P$ (w2 vs w14) & Week 14 & $P$ (w0 vs w14) \\
\hline Resistin, $\mathrm{ng} / \mathrm{mL}$ & $7.3(0.5 ; 14.5)$ & 0.0002 & $14.7(5.1 ; 50.5)$ & $<0.0001$ & $6.9(2.9 ; 16.8)$ & 0.0665 & $9.2(4.1 ; 20.6)$ & 0.0011 \\
\hline Adiponectin, $\mu \mathrm{g} / \mathrm{mL}$ & $8.7(5.0 ; 10.8)$ & 0.6705 & $7.8(4.6 ; 11.9)$ & 0.0005 & $9.2(4.1 ; 20.7)$ & 0.0001 & $6.5(3.0 ; 12.7)$ & 0.0182 \\
\hline Adiponectin, girls, $\mu \mathrm{g} / \mathrm{mL}$ & $8.8(5.0 ; 10.8)$ & 0.9453 & $8.2(6.0 ; 11.1)$ & 0.0078 & $11.7(8.0 ; 17.5)$ & 0.0078 & $7.0(4.9 ; 12.7)$ & 0.9999 \\
\hline Adiponectin, boys, $\mu \mathrm{g} / \mathrm{mL}$ & $8.5(5.6 ; 9.4)$ & 0.4922 & $7.0(4.6 ; 11.9)$ & 0.0645 & $8.1(4.1 ; 20.7)$ & 0.0098 & $4.7(3.0 ; 7.7)$ & 0.0098 \\
\hline Leptin, $\mathrm{ng} / \mathrm{mL}$ & $3.6(1.2 ; 15.7)$ & 0.8986 & $3.2(0.6 ; 30.1)$ & 0.0047 & $6.4(1.7 ; 35.2)$ & 0.8986 & $4.3(1.3 ; 26.8)$ & 0.0208 \\
\hline Leptin, girls, ng/mL & $10.1(3.2 ; 15.7)$ & 0.9999 & $9.5(4.0 ; 30.1)$ & 0.0156 & $16.0(7.9 ; 35.2)$ & 0.7422 & $17.2(10.8 ; 26.8)$ & 0.1953 \\
\hline Leptin, boys, ng/mL & $2.1(1.2 ; 4.1)$ & 0.6250 & $2.0(0.6 ; 12.9)$ & 0.0840 & $2.8(1.7 ; 8.6)$ & 0.5566 & $3.3(1.3 ; 4.6)$ & 0.1309 \\
\hline BMI, $\mathrm{kg} / \mathrm{m}^{2}$ & $18.4(2.0)$ & 0.0979 & $18.0(2.2)$ & 0.0077 & $18.2(2.1)$ & 0.0046 & $19.1(2.2)$ & 0.0009 \\
\hline Height, $\mathrm{cm}$ & $156.5(15.0)$ & 0.1428 & $161.0(9.9)$ & 0.0067 & $161.4(9.8)$ & $<\mathbf{0 . 0 0 0 1}$ & $162.8(9.8)$ & $<\mathbf{0 . 0 0 0 1}$ \\
\hline wPCDAI & & & $26.3(7.5 ; 72.5)$ & $<0.0001$ & $15.0(0 ; 35.0)$ & 0.0837 & $8.8(0 ; 45.0)$ & 0.0003 \\
\hline $\mathrm{CRP}, \mathrm{mg} / \mathrm{dL}$ & & & $1.4(0 ; 6.3)$ & $<\mathbf{0 . 0 0 0 1}$ & $0.1(0 ; 1.4)$ & 0.1514 & $0.1(0 ; 1.7)$ & 0.0009 \\
\hline $\mathrm{ESR}, \mathrm{mm} / \mathrm{h}$ & & & $40(8 ; 67)$ & 0.0037 & $21(2 ; 44)$ & 0.3968 & $18(2 ; 40)$ & 0.0004 \\
\hline Albumin, $\mathrm{g} / \mathrm{dL}$ & & & $4(3.2 ; 4.9)$ & 0.0002 & $4.2(3.4 ; 5)$ & 0.1642 & $4.4(3.9 ; 4.8)$ & 0.0035 \\
\hline Hematocrit, \% & & & $36(32 ; 43)$ & $<0.001$ & $38(33 ; 46)$ & 0.1108 & $38(29 ; 44)$ & 0.3519 \\
\hline
\end{tabular}

Serum adipokines, disease activity, inflammatory and anthropometric parameters in healthy controls (HC) and in patients under infliximab therapy: values at baseline (week 0, w0), at second infliximab infusion (week 2, w2), and at fourth infliximab infusion (week 14, w14). Adipokines, disease activity, and inflammatory parameters expressed as median (range), differences were analyzed with Wilcoxon matched-pairs signed rank test. Anthropometric parameters expressed as mean (standard deviation), differences were analyzed with paired $t$-test. $\mathrm{BMI}=$ body mass index, $\mathrm{CRP}=\mathrm{C}$-reactive protein, $\mathrm{ESR}=\mathrm{erythrocyte}$ sedimentation rate, $\mathrm{N}=$ number of patients, $\mathrm{wPCDAI}=$ mathematically weighted Pediatric Crohn's Disease Activity Index.

Bold values were used for significant effects. 
A

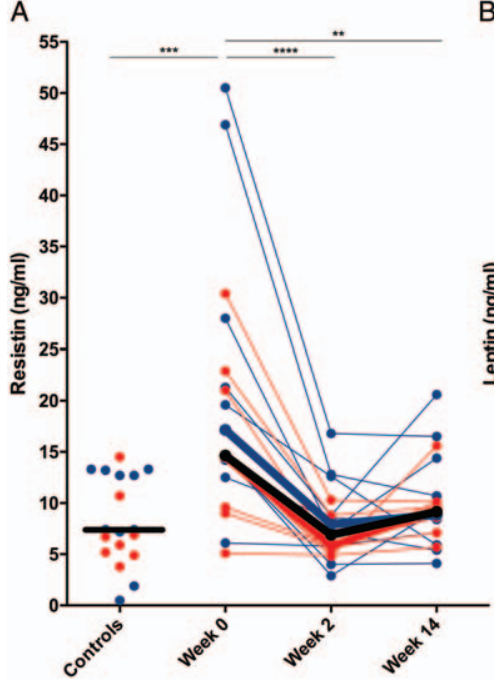

B

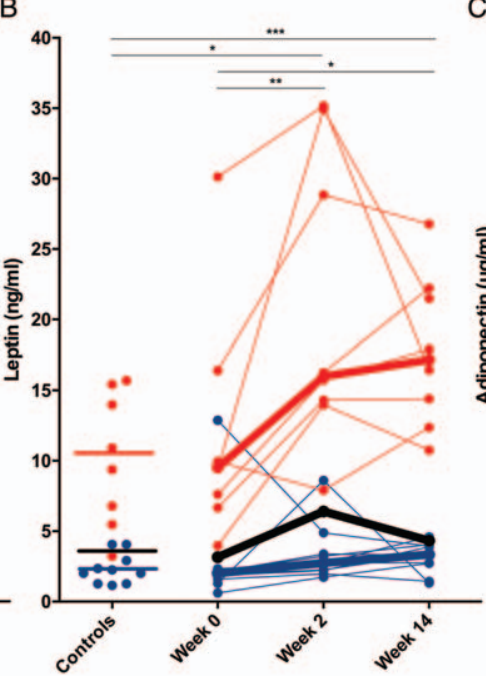

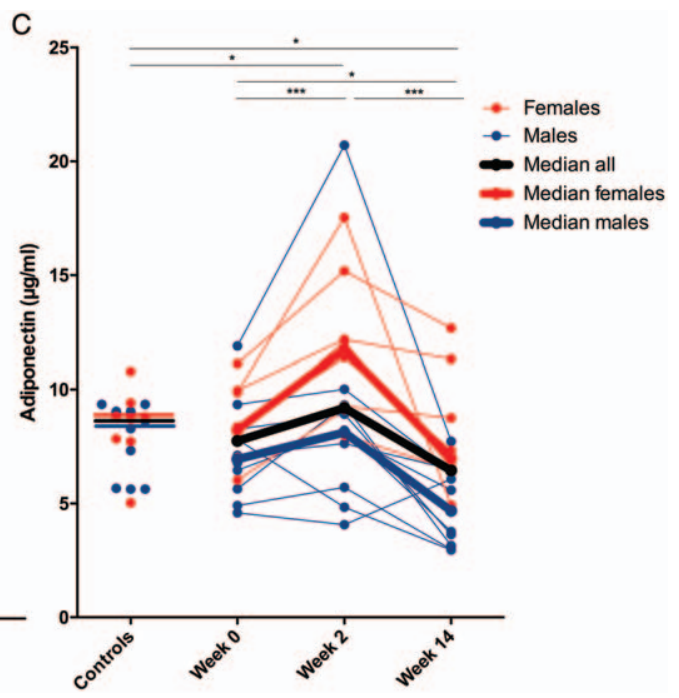

FIGURE 1. Serum adipokine levels according to sex in healthy controls and in CD patients at baseline (week 0 ) and under infliximab therapy (weeks 2 and 14) displaying each patient individually and the median lines $(n=18)$. (A) Resistin levels were higher in $C D$ at baseline, decreased under therapy and showed no sex differences. (B) Leptin was significantly higher in girls at all time points and increased under IFX. (C) Adiponectin tended to be higher in girls, peaked 2 weeks after first IFX infusion and thereafter decreased. Differences were analyzed with Wilcoxon matchedpairs signed rank test. ${ }^{*} P<0.05,{ }^{* *} P<0.01,{ }^{* * *} P<0.001,{ }^{* * * *} P<0.0001 . \mathrm{CD}=$ Crohn disease, $\mathrm{HC}=$ healthy controls, IFX $=$ infliximab.

adipocytes in humans. TNF and lipopolysaccharide stimulate resistin release in human $\mathrm{PBMCs}$, whereas resistin upregulates TNF, IL-6 and IL-1 $\beta$ mRNA expression, and protein release (18). Increased resistin expression in the mesenteric adipose tissue in CD indicates unspecific inflammation (8). A decrease in resistin was suggested as a biomarker of successful IFX treatment in adults (34). In agreement with previous studies $(22,34)$, we found high resistin serum levels in active $\mathrm{CD}$ compared with control children and observed a decrease under IFX induction therapy. In our cohort, resistin levels correlated with the inflammatory parameter CRP as previously reported in patients with rheumatoid arthritis (35).

Leptin reflects body fat mass and has several metabolic functions. In patients with acute inflammation, like sepsis, leptin concentrations are increased (36). On the other hand, under conditions of chronic inflammation and in in vitro models of human adipose tissue, leptin release is inhibited by TNF (15). As serum levels of leptin are affected by sex and body composition, we selected sex- and BMI-matched HC. At baseline, we found similar leptin levels compared with BMI-matched $\mathrm{HC}$, which is consistent with previous observations $(19,22,24)$. Whenever children with IBD, however, were compared with age and sex, but not BMImatched controls, leptin levels were lower, reflecting reduced total body fat (20). In line with others (19) we found leptin levels significantly higher in girls. In agreement with previous studies, leptin levels increased in the first weeks after starting IFX therapy $(34,37)$. Franchimont et al (37) suggested that the chronic inhibitory effect of TNF on leptin release is blocked by IFX and resulted in increased leptin levels in a fat mass-independent manner. Serum TNF levels, however, were not measured in this study. Contrary to their results, in our cohort, IFX therapy led to a significant improvement in BMI. Increased appetite and weight gain following TNF blockade might be an additional mechanism explaining elevation of leptin levels under IFX induction therapy.

In vitro studies with human adipocytes and adipocyte cell lines demonstrated that TNF inhibits adiponectin secretion $(15,38,39)$. Results on adiponectin in IBD patients are controversial with one study reporting slightly elevated (21), others decreased serum adiponectin levels $(22,23,40)$. In our CD patients, adiponectin at baseline was similar to sex- and BMI-matched children. The marked increase of the adiponectin levels in our cohort after the first IFX infusion was surprising. This early hyperadiponectinemia could reflect adiponectin release through TNF blockade considering that the IFX drug levels are almost 10 times higher before second infusion after 2 weeks compared with the trough levels before the fourth infusion at week 14 (41). These higher IFX concentrations at week 2 compared with week 14 may explain that the changes in resistin and adiponectin concentrations from week 2 to baseline are stronger compared with the changes from week 14 to baseline. Our findings are supported by a similar hyperadiponectinemia reported in patients with rheumatoid arthritis during the induction phase of anti-TNF therapy (42). Adiponectin significantly decreased in our cohort at week 14. Similarly, Karmiris et al (34) reported a trend to lower adiponectin levels in adult IBD patients (17 with $\mathrm{CD}$ and 3 with ulcerative colitis) 4 months after starting IFX. No earlier measurements were performed in their patients.

We report an interesting observation in patients receiving IFX therapy. Due to the lack of, however, a comparator group we cannot answer whether this is an IFX-specific effect or an effect associated with successful induction treatment in pediatric $\mathrm{CD}$ in general. Limitations of our study include the number of patients with a spectrum of disease activity, disease behaviour, and treatment response, which precludes subgroup analysis. The retrospective character did only allow assessment of improved body composition according to changes in anthropometric parameters but not of objective data on changes in abdominal adipose tissue volumes measurable by MRI. A further limitation is the measurement of steady state, circulating leptin, resistin, and total adiponectin levels. The analysis of different serum adiponectin isoforms and adipokine expression in the intra-abdominal adipose tissue might have provided additional information.

In conclusion, anti-TNF therapy is associated with early changes in adipokine levels in pediatric CD. Although serum resistin decreased and leptin increased, serum adiponectin peaked after first IFX infusion. We speculate that the early hyperadiponectinemia induced by IFX may contribute to the successful and rapid anti-inflammatory response. Further investigations on larger cohorts are needed to evaluate the role of early serum adiponectin 
measurements as a biomarker for short- and long-term response to IFX.

Acknowledgments: The authors would like to acknowledge the clinical work, contribution on sample collection, and excellent documentation of Eva Maria Gerstl, Florian Gothe, MohammadSamer Hajji, Kathrin Krohn, Alexandra Fabry-Said, Andrea Sustmann, and Gertraud Ossiander (in alphabetical order). The authors alo thank Gabriele Heilig and Ana-Maria Bulau for technical assistance.

\section{REFERENCES}

1. Crohn BB, Ginzburg L, Oppenheimer GD. Landmark article Oct 15, 1932. Regional ileitis. A pathological and clinical entity. By Burril B. Crohn, Leon Ginzburg, and Gordon D. Oppenheimer. JAMA 1984;251:73-9.

2. Drouet M, Dubuquoy L, Desreumaux P, et al. Visceral fat and gut inflammation. Nutrition 2012;28:113-7.

3. Desreumaux P, Ernst O, Geboes K, et al. Inflammatory alterations in mesenteric adipose tissue in Crohn disease. Gastroenterology 1999; 117:73-81.

4. Kredel LI, Batra A, Stroh T, et al. Adipokines from local fat cells shape the macrophage compartment of the creeping fat in Crohn's disease. Gut 2013;62:852-62.

5. Peyrin-Biroulet L, Chamaillard M, Gonzalez F, et al. Mesenteric fat in Crohn's disease: a pathogenetic hallmark or an innocent bystander? Gut 2007:56:577-83

6. Zulian A, Cancello R, Micheletto G, et al. Visceral adipocytes: old actors in obesity and new protagonists in Crohn's disease? Gut 2012;61:86-94.

7. Barbier M, Vidal H, Desreumaux P, et al. Overexpression of leptin mRNA in mesenteric adipose tissue in inflammatory bowel diseases. Gastroenterol Clin Biol 2003;27:987-91.

8. Paul G, Schaffler A, Neumeier M, et al. Profiling adipocytokine secretion from creeping fat in Crohn's disease. Inflamm Bowel Dis 2006;12:471-7.

9. Yamamoto K, Kiyohara T, Murayama Y, et al. Production of adiponectin, an anti-inflammatory protein, in mesenteric adipose tissue in Crohn's disease. Gut 2005;54:789-96.

10. Peyrin-Biroulet L, Gonzalez F, Dubuquoy L, et al. Mesenteric fat as a source of $\mathrm{C}$ reactive protein and as a target for bacterial translocation in Crohn's disease. Gut 2012;61:78-85.

11. Batra A, Pietsch J, Fedke I, et al. Leptin-dependent toll-like receptor expression and responsiveness in preadipocytes and adipocytes. Am J Pathol 2007;170:1931-41.

12. Saillan-Barreau C, Cousin B, Andre M, et al. Human adipose cells as candidates in defense and tissue remodeling phenomena. Biochem Biophys Res Commun 2003;309:502-5.

13. Loffreda S, Yang SQ, Lin HZ, et al. Leptin regulates proinflammatory immune responses. FASEB $J$ 1998;12:57-65.

14. Wolf AM, Wolf D, Rumpold $\mathrm{H}$, et al. Adiponectin induces the antiinflammatory cytokines IL-10 and IL-1RA in human leukocytes. Biochem Biophys Res Commun 2004;323:630-5.

15. Bruun JM, Pedersen SB, Kristensen K, et al. Effects of pro-inflammatory cytokines and chemokines on leptin production in human adipose tissue in vitro. Mol Cell Endocrinol 2002;190:91-9.

16. Patel L, Buckels AC, Kinghorn IJ, et al. Resistin is expressed in human macrophages and directly regulated by PPAR gamma activators. Biochem Biophys Res Commun 2003;300:472-6.

17. Fawcett RL, Waechter AS, Williams LB, et al. Tumor necrosis factoralpha inhibits leptin production in subcutaneous and omental adipocytes from morbidly obese humans. J Clin Endocrinol Metab 2000;85:530-5.

18. Bokarewa M, Nagaev I, Dahlberg L, et al. Resistin, an adipokine with potent proinflammatory properties. J Immunol 2005;174:5789-95.

19. Hoppin AG, Kaplan LM, Zurakowski D, et al. Serum leptin in children and young adults with inflammatory bowel disease. J Pediatr Gastroenterol Nutr 1998;26:500-5.

20. Aurangzeb B, Leach ST, Lemberg DA, et al. Assessment of nutritional status and serum leptin in children with inflammatory bowel disease. J Pediatr Gastroenterol Nutr 2011:52:536-41.
21. Karmiris K, Koutroubakis IE, Xidakis C, et al. Circulating levels of leptin, adiponectin, resistin, and ghrelin in inflammatory bowel disease. Inflamm Bowel Dis 2006;12:100-5.

22. Valentini L, Wirth EK, Schweizer U, et al. Circulating adipokines and the protective effects of hyperinsulinemia in inflammatory bowel disease. Nutrition 2009;25:172-81.

23. Weigert J, Obermeier F, Neumeier M, et al. Circulating levels of chemerin and adiponectin are higher in ulcerative colitis and chemerin is elevated in Crohn's disease. Inflamm Bowel Dis 2010;16:630-7.

24. Rodrigues VS, Milanski M, Fagundes JJ, et al. Serum levels and mesenteric fat tissue expression of adiponectin and leptin in patients with Crohn's disease. Clin Exp Immunol 2012;170:358-64.

25. Ruemmele FM, Veres G, Kolho KL, et al. Consensus guidelines of ECCO/ESPGHAN on the medical management of pediatric Crohn's disease. J Crohns Colitis 2014;8:1179-207.

26. de Bie CI, Escher JC, de Ridder L. Antitumor necrosis factor treatment for pediatric inflammatory bowel disease. Inflamm Bowel Dis 2012; 18:985-1002.

27. IBD Working Group of the European Society for Paediatric Gastroenterology HaN Inflammatory bowel disease in children and adolescents: recommendations for diagnosis-the Porto criteria. J Pediatr Gastroenterol Nutr 2005;41:1-7.

28. Levine A, Griffiths A, Markowitz J, et al. Pediatric modification of the Montreal classification for inflammatory bowel disease: the Paris classification. Inflamm Bowel Dis 2011;17:1314-21.

29. Hyams J, Crandall W, Kugathasan S, et al. Induction and maintenance infliximab therapy for the treatment of moderate-to-severe Crohn's disease in children. Gastroenterology 2007;132:863-73.

30. Freudenberg F, Gothe F, Beigel F, et al. Serum 7-alpha-hydroxy-4cholesten-3-one as a marker for bile acid loss in children. $J$ Pediatr 2013;163:1367-71e1.

31. Turner D, Griffiths AM, Walters TD, et al. Mathematical weighting of the pediatric Crohn's disease activity index (PCDAI) and comparison with its other short versions. Inflamm Bowel Dis 2012;18:55-62.

32. Frivolt K, Hetterich H, Schwerd T, et al. Increase of intra-abdominal adipose tissue in pediatric Crohn's disease. J Pediatr Gastroenterol Nutr 2017;65:633-8.

33. Parmentier-Decrucq E, Duhamel A, Ernst O, et al. Effects of infliximab therapy on abdominal fat and metabolic profile in patients with Crohn's disease. Inflamm Bowel Dis 2009;15:1476-84.

34. Karmiris K, Koutroubakis IE, Xidakis C, et al. The effect of infliximab on circulating levels of leptin, adiponectin and resistin in patients with inflammatory bowel disease. Eur J Gastroenterol Hepatol 2007; 19:789-94.

35. Gonzalez-Gay MA, Garcia-Unzueta MT, Gonzalez-Juanatey C, et al. Anti-TNF-alpha therapy modulates resistin in patients with rheumatoid arthritis. Clin Exp Rheumatol 2008;26:311-6.

36. Bornstein SR, Licinio J, Tauchnitz R, et al. Plasma leptin levels are increased in survivors of acute sepsis: associated loss of diurnal rhythm, in cortisol and leptin secretion. J Clin Endocrinol Metab 1998;83: $280-3$.

37. Franchimont $\mathrm{D}$, Roland $\mathrm{S}$, Gustot $\mathrm{T}$, et al. Impact of infliximab on serum leptin levels in patients with Crohn's disease. J Clin Endocrinol Metab 2005;90:3510-6.

38. Bruun JM, Lihn AS, Verdich C, et al. Regulation of adiponectin by adipose tissue-derived cytokines: in vivo and in vitro investigations in humans. Am J Physiol Endocrinol Metab 2003;285:E527-33.

39. Degawa-Yamauchi M, Moss KA, Bovenkerk JE, et al. Regulation of adiponectin expression in human adipocytes: effects of adiposity, glucocorticoids, and tumor necrosis factor alpha. Obes Res 2005; 13:662-9.

40. Bozic B, Loncar G, Prodanovic N, et al. Relationship between high circulating adiponectin with bone mineral density and bone metabolism in elderly males with chronic heart failure. J Card Fail 2010;16:301-7.

41. Fasanmade AA, Adedokun OJ, Blank M, et al. Pharmacokinetic properties of infliximab in children and adults with Crohn's disease: a retrospective analysis of data from 2 phase III clinical trials. Clin Ther 2011;33:946-64.

42. Komai N, Morita Y, Sakuta T, et al. Anti-tumor necrosis factor therapy increases serum adiponectin levels with the improvement of endothelial dysfunction in patients with rheumatoid arthritis. Mod Rheumatol 2007:17:385-90. 